\title{
Socio-Economic Vulnerability to COVID-19: The Spatial Case of Greater Kampala Metropolitan Area (GKMA)
}

\author{
Ivan Bamweyana1,2,3, Daniel A. Okello4, Ronald Ssengendo ${ }^{2,3}$, Allan Mazimwe ${ }^{2}$, Patrick 0jirot ${ }^{1}$, \\ Fahad Mubiru ${ }^{1,3}$, Laban Ndungo ${ }^{5}$, Consolate N. Kiyingi ${ }^{1}$, Alex Ndyabakira ${ }^{4}$, Sheila Bamweyana ${ }^{6}$, \\ Flavia Zabali ${ }^{1}$
}

\author{
${ }^{1}$ Directorate of Physical Planning, Kampala Capital City Authority, Kampala, Uganda \\ ${ }^{2}$ Department of Geomatics and Land Management Makerere University, Kampala, Uganda \\ ${ }^{3}$ Land Surveying Chapter, Institution of Surveyors, Uganda, Kampala \\ ${ }^{4}$ Directorate of Public Health and Environment, Kampala Capital City Authority, Kampala, Uganda \\ ${ }^{5}$ Solutions Team, Esri Eastern Africa, Nairobi, Kenya \\ ${ }^{6} \mathrm{MU}-J H U$ Research Collaboration, Makerere University, Kampala, Uganda \\ Email: ivanson5@gmail.com
}

How to cite this paper: Bamweyana, I., Okello, D.A., Ssengendo, R., Mazimwe, A., Ojirot, P., Mubiru, F., Ndungo, L., Kiyingi, C.N., Ndyabakira, A., Bamweyana, S. and Zabali, F. (2020) Socio-Economic Vulnerability to COVID-19: The Spatial Case of Greater Kampala Metropolitan Area (GKMA). Journal of Geographic Information System, 12, 302-318.

https://doi.org/10.4236/jgis.2020.124019

Received: June 7, 2020

Accepted: July 21, 2020

Published: July 24, 2020

Copyright $\odot 2020$ by author(s) and Scientific Research Publishing Inc. This work is licensed under the Creative Commons Attribution International License (CC BY 4.0).

http://creativecommons.org/licenses/by/4.0/ cc) (i) Open Access

\begin{abstract}
COVID-19 has presented itself with an extreme impact on the resources of its epi-centres. In Uganda, there is uncertainty about what will happen especially in the main urban hub, the Greater Kampala Metropolitan Area (GKMA). Consequently, public health professionals have scrambled into resource-driven strategies and planning to tame the spread. This paper, therefore, deploys spatial modelling to contribute to an understanding of the spatial variation of COVID-19 vulnerability in the GKMA using the socio-economic characteristics of the region. Based on expert opinion on the prevailing novel Coronavirus, spatially driven indicators were generated to assess vulnerability. Through an online survey and auxiliary datasets, these indicators were transformed, classified, and weighted based on the BBC vulnerability framework. These were spatially modelled to assess the vulnerability indices. The resultant continuous indices were aggregated, explicitly zoned, classified, and ranked based on parishes. The resultant spatial nature of vulnerability to COVID-19 in the GKMA sprawls out of major urban areas, diffuses into the peri-urban, and thins into the sparsely populated areas. The high levels of vulnerability (24.5\% parishes) are concentrated in the major towns where there are many shopping malls, transactional offices, and transport hubs. Nearly half the total parishes in the GKMA (47.3\%) were moderately vulnerable, these constituted mainly the parishes on the outskirts of the major towns while $28.2 \%$ had a low vulnerability. The spatial
\end{abstract}


approach presented in this paper contributes to providing a rapid assessment of the socio-economic vulnerability based on administrative decision units-parishes. This essentially equips the public health domain with the right diagnosis to subject the highly exposed and vulnerable communities to regulatory policy, increase resilience incentives in low adaptive areas and optimally deploy resources to avoid the emancipation of high susceptibility areas into an epicentre of Covid-19.

\section{Keywords}

COVID-19, Socio-Economic Vulnerability, Spatial Modelling, Greater Kampala Metropolitan Area

\section{Introduction}

The outbreak of the novel Coronavirus (SARS-CoV-2) in China in December 2019 as a pathogen transmitted by the respiratory route leading to COVID-19 pandemic [1], has refocused the global attention on regional, national, and local spread suppression of a disease that is inherent to social interaction. In Africa, most countries are woefully unprepared for impact [2]. They are plagued by weak; health systems, financial muscle, surveillance, and laboratory capacity [3]. In African urban communities, many people live together in close quarters. This makes social distancing, a critical prevention strategy in combating COVID-19 problematic to implement [2] to the urban vulnerable population.

Uganda registered her first case of COVID-19 on $21^{\text {st }}$ March 2020. However, by $18^{\text {th }}$ March 2020, the President had issued 25 lockdown related guidelines [4]. This was geared towards impelling the level of transmission to interrupt the growth of the epidemic in Uganda's highly socializing society. Like most countries, the major route of slowing the pandemic and peak health care demand is mitigation through social distancing and isolating suspected cases and their households. However, the Ministry of Health $(\mathrm{MoH})$ in Uganda quickly noted that this would not work in set-ups with a large number of youth $(75 \%$ of the population), overcrowded urban areas, and business centres [4]. This is typical of the Greater Kampala Metropolitan Area (GKMA). It has been registered as the most populated region in Uganda with over seven million people as of 2020 by day population [5]. However, social-economic vulnerability to COVID-19 in this area can be assessed and scaled to smaller administration units (parishes) to infuse policy with timely information for application of appropriate COVID-19 mitigation measures. This paper, therefore, addresses this issue and contributes to an understanding of the spatial variation of COVID-19 Vulnerability in the GKMA using the socio-economic characteristics of the region.

In the policy context of the COVID-19 pandemic, public health officials have been forced to make decisions based on scarce evidence [6]. Vulnerability, on the other hand, is a well-acknowledged concept in risk reduction [7]. It has been 
used as an incentive to policy tailored towards reducing susceptibilities and strengthening Vector-Borne Diseases (VBDs) resilience independent of the prevalence [8] [9] [10]. Though common in VBDs, social vulnerability assessments have recently proliferated in infectious disease management [11] [12]. Vulnerability in itself is complex phenomenal and estimating its value in a given space is a highly dimensional problem affected by a diverse range of anthropological, environmental, socio-economical, and political drivers [13] [14] plus a further niche in the context and application. The International Strategy for Disaster Reduction (ISDR) [15] describes Vulnerability as "the conditions determined by physical, social, economic and environmental factors or processes, which increase the susceptibility of a community to the impact of hazards". In the near contrast, the United National Development Programme (UNDP) defines vulnerability as "a human condition or process resulting from physical, social, economic, and environmental factors, which determine the likelihood and scale of damage from the impact of a given hazard" [16]. Given the social context of Covid-19, this study inclines itself to the ISDR definition. Therefore, the concept of vulnerability herein refers to the conditions determined by physical, demographic, economic, social and environmental factors or processes, which increase the susceptibility of communities in the GKMA to the impact of COVID-19 at any given magnitude and expressed on a scale from 0 (almost no damage) to 1 (total damage).

The resounding objective of this paper is, therefore, to perform a rapid administratively explicit spatial assessment and evaluation of the relative levels of socio-economic vulnerability between the different parishes in the GKMA, independent of the COVID-19 prevalence. In essence, this will model the predisposition of the population in GKMA to being adversely affected by the pandemic. Based on the holistic framework of vulnerability and the novel nature of COVID-19, we exploit expert-based approaches for analysis and aggregation of the socio-economic and demographic indicators.

\subsection{Conceptualization of Vulnerability}

There are many measures by which vulnerability is assessed [17], this assessment of vulnerability adopts the BBC framework [18]. This framework accounts for the interaction of demographics, economic and political exposure in configuring vulnerability [19] these are pivotal in the prevalence of COVID-19. This framework allows for the conceptualization of multi-dimensional and complex nature of vulnerability at different spatial scales. Here, vulnerability is characterized into three factors; Exposure, Susceptibility, and Copying/Adaptive Capacity as shown in Figure 1. Concerning COVID-19 in GKMA; Exposure herein refers to people, property, systems, or other elements present in impact zones that are thereby subject to potential losses resulting from the Impact, Susceptibility herein refers to factors inherent to the physical predisposition of COVID-19, Adaptive Capacity herein refers to a combination of strengths and 


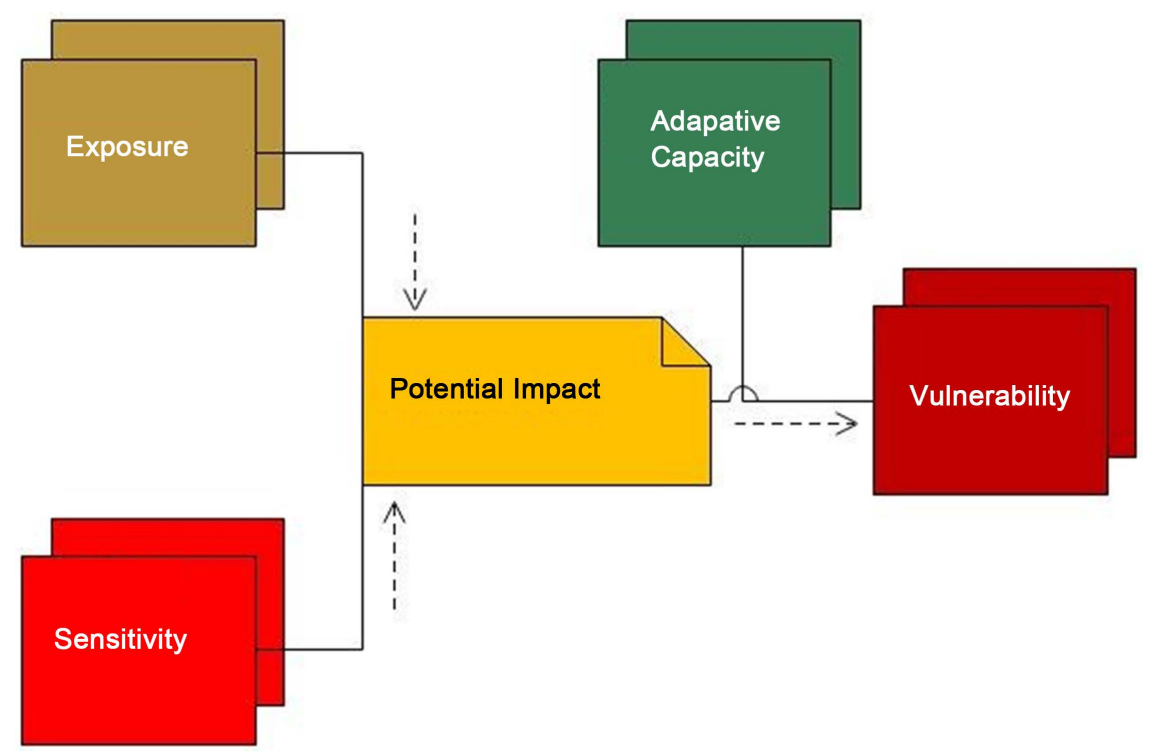

Figure 1. Conceptual framework [20].

resources available within a community or organization that can reduce the effect of COVID-19.

\subsection{Vulnerability Assessment in the Health Domain}

Statistical and probabilistic methods have been used to assess vulnerability in the health domain [21] [22]. In these methods, bivariate models such as frequency ratio, principal component analysis are applied on archived data to derive weights that are later used to combine the proxy data to obtain vulnerability. Also, multivariate models can be used to study spatial-temporal relationships and trends between each proxy dataset and vulnerability. From these, a family of methods and approaches [23] exists depending on the context and source of data. This research adopted the Indicator based. This methodology integrates scientific knowledge, local expert opinions, historical data, and national spatial data infrastructures. Furthermore, the methodology provides for model improvement since it allows flexible addition of new indicator datasets.

\section{Methods}

\subsection{Study Area}

Greater Kampala Metropolitan Area (GKMA) shown in Figure 2 consists of the capital city Kampala and the part of neighbouring Wakiso District, Mukono District, Mpigi District, Buikwe District, and Luweero District. It is the most densely populated city landmass in Uganda with a rapidly growing population that is estimated at 7 million people (day population) in 2020 by the Uganda Bureau of Statistics (UBOS) in an area of $8451.9 \mathrm{~km}^{2}$. Major urban centers in the Greater Kampala Metropolitan Area include Kampala City, Entebbe, Mukono, Wakiso Town, Kira, and Nansana Municipality. 


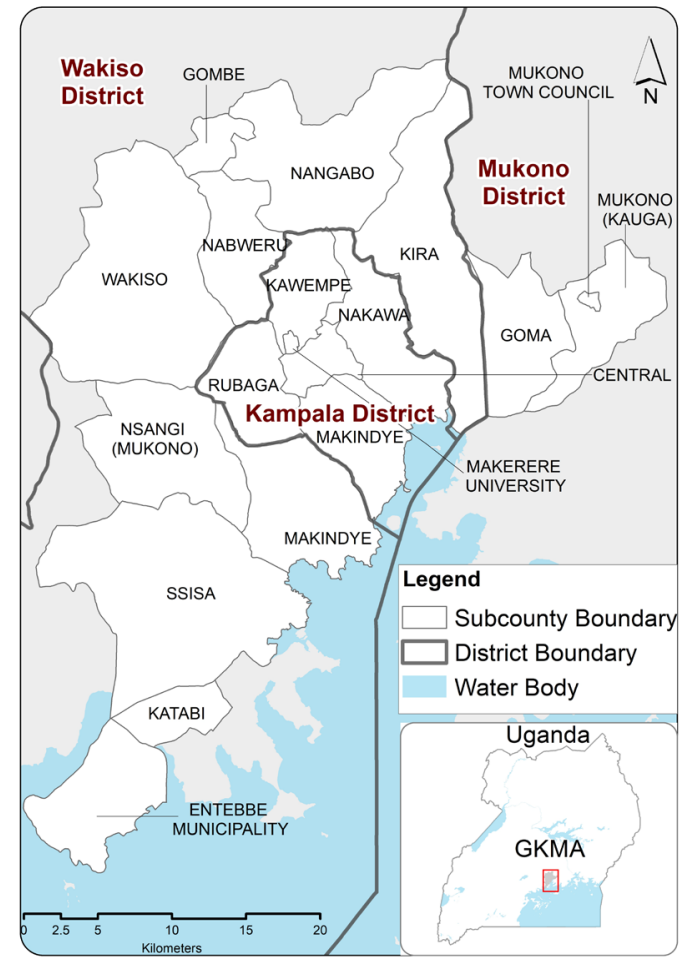

Figure 2. Greater Kampala Metropolitan Area (GKMA).

\subsection{Modelling Workflow}

To encompass the multi-facet nature of the vulnerability, the study adopted mixed research design [24] to answer the research questions on which areas in the metropolitan area are most, exposed, susceptible, adaptable, and vulnerable to COVID-19 pandemic. The study workflow (Figure 3) follows the OECD [25] guidelines. The major components of the workflow include; 1 ) Definition of the vulnerability framework; 2) determining a matrix of indicators classified to the intricacies of exposure, adaptive capacity and susceptibility to COVID-19 based on the review of literature and stakeholder expert consultations; 3) Data Collection (primary and secondary data), primary data collection involved running an online survey in the region to ascertain current pre-existing medical conditions and income levels, secondary data methods involved mining historical datasets. 4) Data analysis and spatial transformations; 5) normalisation; 6) weighting; 7) Multi-Criteria Decision Analysis (MCDA) in the different vulnerability domains; 8) aggregation for the vulnerability index; 9) Scaling to the administrative unit (parish); 10) Visualisation.

\subsection{Parameters}

Given the methodology adopted was indicator based, expert stakeholder consultations were conducted to identify the required indicators. The experts were mainly drawn from the public health, social sciences, and geo-information science domains. 12 indicators were selected to determine COVID-19 vulnerability (5 Exposure, 5 Adaptive Capacity, and 2 Susceptibility). These were 


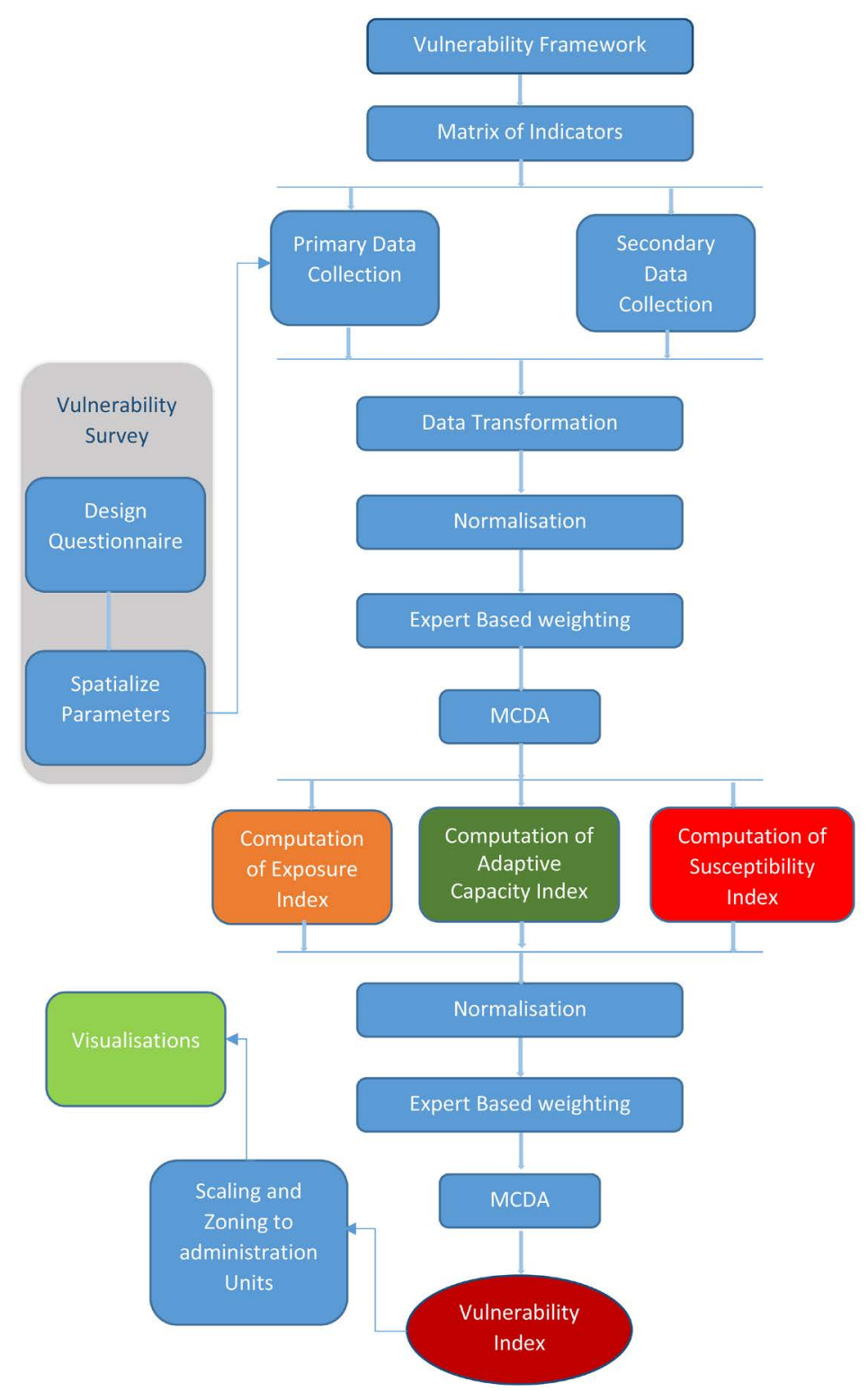

Figure 3. Study design and workflow.

selected depending on the available data, the difference in representation, influence and significance to the analysis, and the spatial and temporal relevance to the dynamics of COVID-19 Impact.

\subsection{Data Collection}

The data was collected in two clusters, the secondary data, and primary data. Secondary data was mainly through data mining already existing datasets. Primary data on the hand was mainly generated through a social-economic survey, with an estimated population of close to 5 million by night and 7 million people by day, a representative sample was computed using Krejcie and Morgan method [26].

The sample size $(n)$ is calculated according to the formula: 


$$
n=\left[z^{2} * p *(1-p) / e^{2}\right] /\left[1+\left(z^{2} * p *(1-p) /\left(e^{2} * N\right)\right)\right]
$$

where: $z=1.96$ for a confidence level $(\alpha)$ of $95 \%, p=$ proportion (expressed as a decimal), $N=$ population size, $e=$ margin of error.

However, besides the statistical sampling, spatial distribution across the study area was also considered through the re-run of the survey in areas of low responsiveness.

\subsection{Data Transformation}

To initiate analysis, the data is transformed into surfaces, these must-have similar characteristics such as coordinate transformation, spatial extent, pixel size. This was achieved by subjecting the data to re-projection, resampling, interpolation, and aggregation.

\subsection{Data Normalization}

Since indicators used in this assessment have different measurements, normalization is carried out to render them comparable before the aggregation. Several normalization techniques exist [27], this assessment, however, adopted the max-min method, because of its ability to preserve relationships within the data [28] and widen the range of indicators laying within a small interval. The indicators are assigned in an identical range, 0 - 1.

In the min-max normalization [24], each indicator $x_{q c}^{t}$ for a generic country $\mathrm{c}$ and time $t$ is transformed in;

$$
I_{q c}^{t}=\frac{x_{q c}^{t}-\min _{c}\left(x_{q}^{t}\right)}{\max _{c}\left(x_{q}^{t}\right)-\min _{c}\left(x_{q}^{t}\right)}
$$

where $\min _{c}\left(x_{q}^{t}\right)$ and $\max _{c}\left(x_{q}^{t}\right)$ are the minimum and maximum value of $x_{q c}^{t}$ across all countries $c$ at time $t$. In this way, the normalized indicators $I_{q c}$ have values lying between 0 (laggard, $x_{q c}^{t}=\min _{c}\left(x_{q}^{t}\right)$ ), 1 (leader, $\left.x_{q c}^{t}=\max _{c}\left(x_{q}^{t}\right)\right)$.

\subsection{Multi-Criteria Decision Analysis (MCDA)—Weighting and Aggregation}

MCDA is a collection of formal approaches which seek to take explicit account of key factors in helping individuals or groups explore decisions that matter [29]. Accordingly, this empowers MCDA procedures as decision rules defining the relationship between the input map and output map using geographical data, decision maker's preferences data manipulation, and preferences according to decision rules [30]. The preferences are then incorporated into the decision model in terms of weights or importance assigned to them during evaluation. Over the past decade, several multi-criteria evaluation methods were introduced in the GIS environment [31]. This assessment adopted expert based weighting. This technique is transparent, short, and relatively straight forward [24], however, it's also highly subjective. In this case, it was adopted as the assessment was 
run parallel to the prevailing COVID-19 spread mitigation efforts.

Aggregation is a process of combining several values into a single one so that the final result of aggregation takes into account a given manner all the individual values [32]. There are several ways in which indicators can be aggregated in MCDA [30]. Of these, the Weighted Linear Combination (WLC) and boolean overlay functions such as intersection (AND) and union (OR) are considered straight forward and most employed in the GIS environment [33]. This assessment opted for the WLC which multiplies normalized criteria scores by relative weights for each sub-indicator [34]. The total score is then obtained by multiplying the weight $(w)$ assigned to each sub-indicator $(x)$, the normalized value in given criteria then summing the products overall Index (I) [30].

$$
I=\sum w_{i} x_{i}
$$

Zonal statistics are them deployed to generate aggregate values for the administrative units.

From our framework, vulnerability $(V)$ is a function of Exposure Index (EI), Susceptibility Index (SI), and Adaptive Capacity Index (ACI); $V=f($ EI, SI, ACI). In a study on vulnerability aggregation algorithms [35], Equation (4) resulted in a more uniform distribution in the different intervals. This study, therefore, adopted the same aggregation model.

$$
V=\mathrm{EI}+\mathrm{SI}+\mathrm{ACI}
$$

\section{Results and Discussion}

\subsection{Vulnerability Indicators}

A composite of 12 indicators were identified and weighted for the construction of the composites by the expert team. This was mainly hinged on the availability, influence, and relevancy of data. Table 1 provides an overview of the final set of indicators, the representative domain, the indicator and domain weights, the proxy of the data, and the source of the data. A total of 6830 respondents were obtained from the vulnerability survey.

\subsection{Vulnerability Composites}

Vulnerability composites were generated as shown in Figures 4(a)-(c) represent adaptive capacity, exposure and susceptibility indices respectively. Whereas vulnerability is often represented on a continuous surface, this study zoned its representation explicitly to the desired variation based on administrative units called parishes. Uganda's administrative units are arranged into; Regions, Districts, Counties, Sub counties/divisions, Parishes/Ward and the smallest unit centers deployed and supported called health centre IIs. These serve at the parish Villages/Cell. In the health domain, the smallest formal health management level. Consequently, the vulnerability variation was assessed at the parish level. Figure 5 shows the statistical impact of the different composites on the parishes. Here, the scale of impact is divided into 3 clusters; High, Moderate and Low. 
Table 1. Indicators and respective weights for the expert based vulnerability index composite.

\begin{tabular}{|c|c|c|c|c|c|}
\hline Indicator & Domain & $\begin{array}{l}\text { Indicator } \\
\text { Weights }\end{array}$ & $\begin{array}{l}\text { Domain } \\
\text { Weight }\end{array}$ & Proxy & $\begin{array}{l}\text { Source of } \\
\text { spatial data }\end{array}$ \\
\hline Level of income & AI & 0.4 & & Income level index & $\begin{array}{l}\text { Vulnerability } \\
\text { Survey }\end{array}$ \\
\hline $\begin{array}{c}\text { Access to } \\
\text { good Health Care }\end{array}$ & AI & 0.2 & & $\begin{array}{l}\text { Proximity and } \\
\text { Transport } \\
\text { Health Facility }\end{array}$ & $\begin{array}{l}\text { Vulnerability } \\
\text { Survey }\end{array}$ \\
\hline Mobility & $\mathrm{AI}$ & 0.1 & & $\begin{array}{l}\text { Has Car, bicycle, } \\
\text { motorcycle }\end{array}$ & $\begin{array}{l}\text { Vulnerability } \\
\text { Survey }\end{array}$ \\
\hline Food insecurity & $\mathrm{AI}$ & 0.1 & & $\begin{array}{c}\text { Deployed } \\
\text { food-management } \\
\text { Mechanisms }\end{array}$ & $\begin{array}{l}\text { Vulnerability } \\
\text { Survey }\end{array}$ \\
\hline Balanced diet & AI & 0.2 & 0.25 & $\begin{array}{l}\text { Average dietary } \\
\text { energy } \\
\text { supply adequacy }\end{array}$ & $\begin{array}{l}\text { Vulnerability } \\
\text { Survey }\end{array}$ \\
\hline & & Sum $=1$ & & & \\
\hline Elderly population & SI & 0.4 & & population above 50 & $\begin{array}{l}\text { Vulnerability } \\
\text { Survey }\end{array}$ \\
\hline $\begin{array}{l}\text { Population with } \\
\text { pre-existing } \\
\text { health conditions }\end{array}$ & SI & 0.6 & 0.4 & $\begin{array}{c}\text { Pregnant, } \\
\text { Hypertension, }\end{array}$ & $\begin{array}{l}\text { Vulnerability } \\
\text { Survey }\end{array}$ \\
\hline & & Sum $=1$ & & & \\
\hline Schools & EI & 0.3 & & Schools & $\begin{array}{c}\text { Kampala Capital } \\
\text { City Authority }\end{array}$ \\
\hline $\begin{array}{c}\text { Transactional } \\
\text { offices }\end{array}$ & EI & 0.1 & & $\begin{array}{c}\text { Government and } \\
\text { private } \\
\text { organization offices }\end{array}$ & $\begin{array}{c}\text { Kampala Capital } \\
\text { City Authority }\end{array}$ \\
\hline Transport hubs & EI & 0.3 & & Transport hubs & $\begin{array}{c}\text { Kampala Capital } \\
\text { City Authority }\end{array}$ \\
\hline $\begin{array}{c}\text { Shopping and } \\
\text { Commercial Hubs }\end{array}$ & EI & 0.2 & & $\begin{array}{l}\text { Shopping and } \\
\text { Commercial Hubs }\end{array}$ & $\begin{array}{c}\text { Kampala Capital } \\
\text { City Authority }\end{array}$ \\
\hline \multirow[t]{2}{*}{$\begin{array}{l}\text { Population } \\
\text { density }\end{array}$} & EI & 0.1 & 0.35 & $\begin{array}{l}2020 \text { population } \\
\text { projections }\end{array}$ & $\begin{array}{l}\text { Uganda Bureau } \\
\text { of statistics }\end{array}$ \\
\hline & & Sum $=1$ & Sum $=1$ & & \\
\hline
\end{tabular}

Given the complex nature of vulnerability to infectious disease, and the subjective nature of expert opinion a three cluster classification is used to widen aggregation given the dynamic nature of the factors incorporated for example population that varies by day and night.

\subsection{Adaptive Capacity}

From Figure 4(a), the Centre of the Greater Kampala Metropolitan Area (GKMA) which is the Central Business District (CBD), the far southern part 


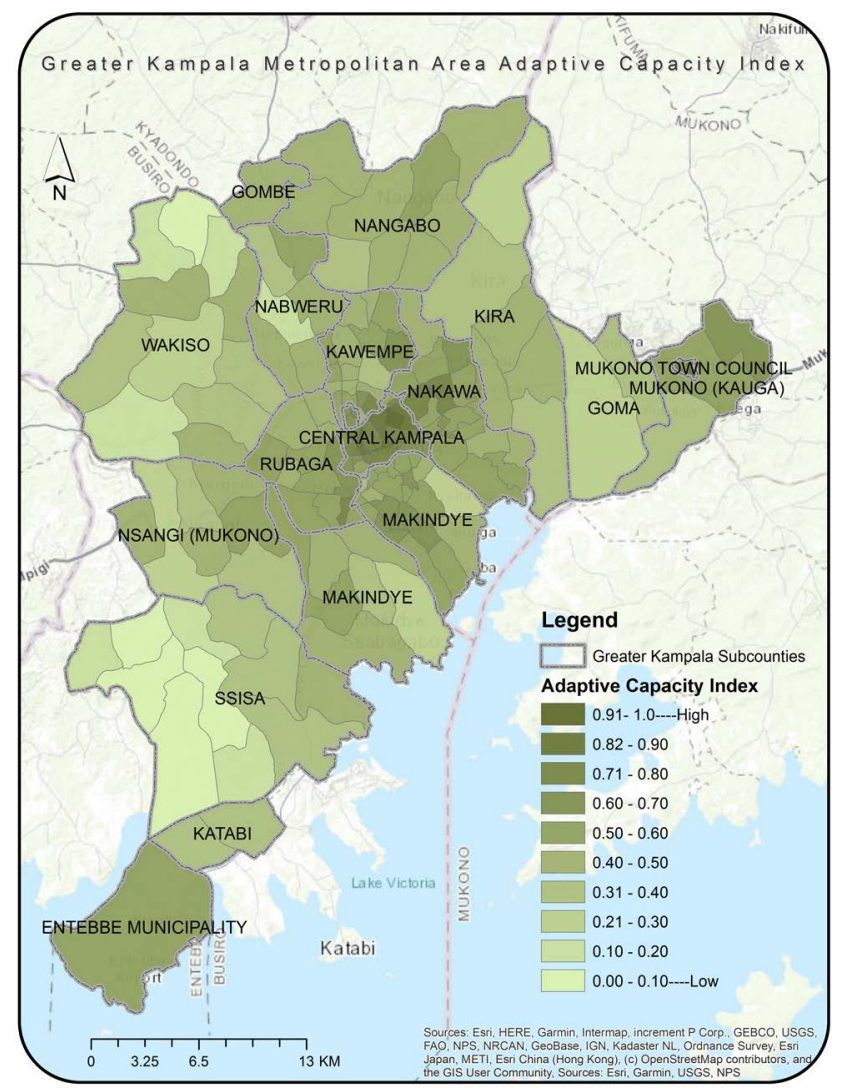

(a)

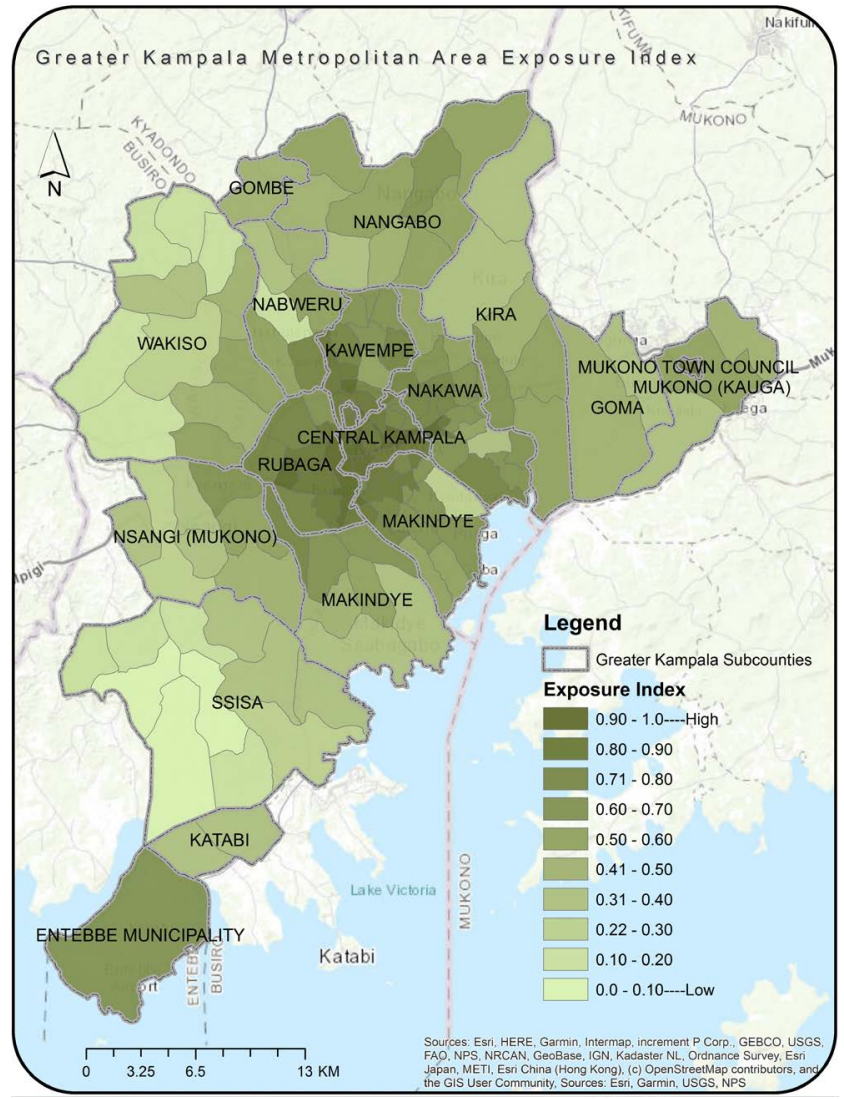

(b) 


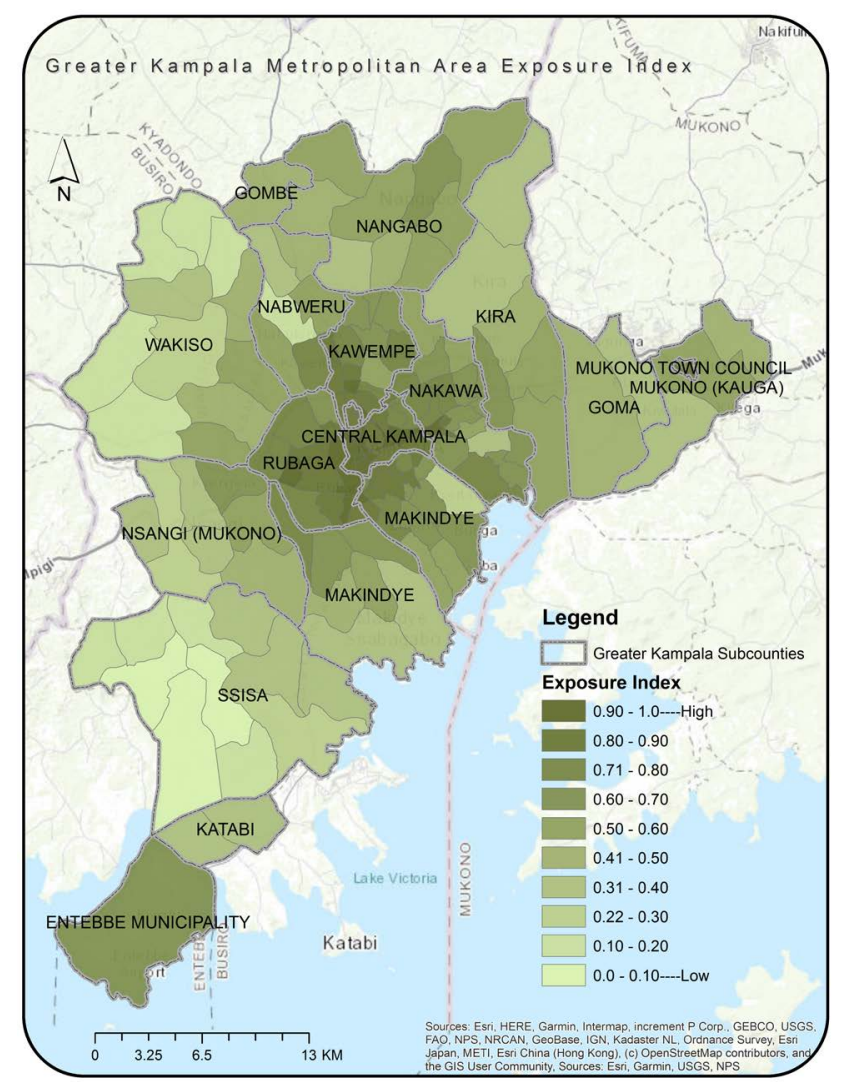

(c)

Figure 4. Showing the adaptive capacity index (a), exposure index (b), and the susceptibility index (c).

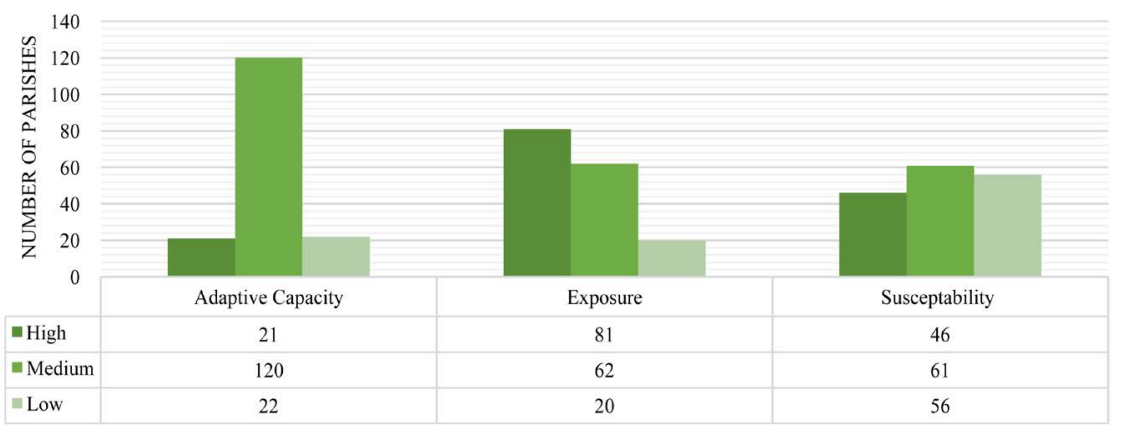

Figure 5. Table showing the number of impacted parishes at different scales.

which is Entebbe municipality that has the Airport, and far East that has Mukono municipality have a high adaptive capacity. From Figure 5, 21 parishes which represent $12.9 \%$ of other parishes in the GKMA also had a high adaptive capacity. These are mainly in urban areas where there is proximity to high-end medical facilities, hyper food markets, and the highest income levels. 120 parishes that represent $74 \%$ of the GKMA were moderately adaptive. The GKMA is the footprint of the Capital City and is therefore flanked by peri-urban areas that house the urban working class that can afford decent feeding, transport to hospitals, and moderate-income to sustain them even in lockdown. 22 parishes 
which represent $13.2 \%$ of the GKMA were observed to have the low adaptive capacity. This was characteristic of; slum areas like Katwe I, and Bbanda, and areas with near village settings like Ssisa, also, areas that are dominated by swamps, scattered households.

\subsection{Exposure}

From Figure 4(b) and Figure 5, the centre of the GKMA, the CBD has a high exposure index, this is the same case in major municipalities like Mukono, Nansana and Entebbe. This accounts for 81 parishes an equivalent of $49.7 \%$ of the total parishes is highly exposed. Areas like Luzira prison parish that's home to the main prison and Makerere III that houses the main university as well as slum areas are in this category. These areas have a relatively high population especially by day, multiple transport hubs, transactional offices as well as shopping and commercial hubs. To control a potential outbreak in these parishes, the restriction should be put on public transport to control the day population influx. 62 parishes that represent $38 \%$ of the parishes in the metropolitan area are moderately exposed. They are mainly peri-urban areas, for example, Nabweru, Katabi, Kikaya. These are observed to be highly residential areas, whereas they have a high population, there is controlled transport, transaction, and shopping interaction. 20 parishes which represent $12.3 \%$ of the parishes in the GKMA were found to have low exposure. These are mainly on the extreme ends of the metropolitan area. These areas are characterized by space population, limited shopping areas, and only stop-over transport points.

\subsection{Susceptibility}

Figure 4(c) and Figure 5 show 46 parishes which represent 28.2\% were highly susceptible. The central to GKMA had the highest concentration with the eastern parishes of being predominant. By the late 19th century, modern-day Kampala was spread out to this area over three major hills: Mengo, the capital (Kibuga) of Buganda Kingdom) and location of the Kabaka's palace (Residence of the King of Buganda), Rubaga, the site of the Catholic mission, and Namirembe, the home of the Protestants [36]. This area had the largest settlements to approximately 77,000 Indigenous Baganda, while Rubaga and Namirembe housed European missionaries and their cohorts. Settlements in these areas have therefore been in existence for long. This explains the high response of the old aged populace in the respective areas. 61 parishes that represent $37.4 \%$ of the parishes were moderately susceptible, this was observed in areas that have recently become residentially dominated, there was an urban shit in the early 2000s to areas which are in Wakiso district but satellite to Kampala [37]. These areas are now believed to have the main urban population between $21-45$, as they have the main rental and residential market. 56 parishes that represent $34.4 \%$ of the parishes had a low susceptibility, these are mainly associated with the urban youth, and dynamic age group settlements. The survey observed a strong correlation of pre-existing conditions with old age. 


\subsection{Vulnerability}

Figure 6, represents the vulnerability index composite, in this composite, 40 parishes which represent $24.5 \%$ of the GKMA were highly vulnerable. These areas are majorly observed in the central enclosing Kampala central and Rubaga sub-counties. Major municipalities like Entebbe and Mukonoin the south and the Far East respectively also presented a high vulnerability index. Whereas the adaptive capacity is good in these areas, exposure and susceptibility are high. This calls for policy interventions as the likelihood of COVID-19 having an impact in this area is high. A big number of parishes, 77 parishes which represent $47.3 \%$ were moderately vulnerable. These are the outskirts of major municipalities and towns. The adaptive capacity is largely moderate in these areas but there are varying levels of exposure and susceptibility. These areas should enhance COVID-19 Control mechanisms concerning the exposure and susceptibility variations. A total of 46 parishes which represent $28.2 \%$ had a low vulnerability. These are in the areas were on the outskirts of peri-urban areas, they are characterized by relatively low population compared to the city centre, longer distances to hospitals, limited transaction offices, shopping, and

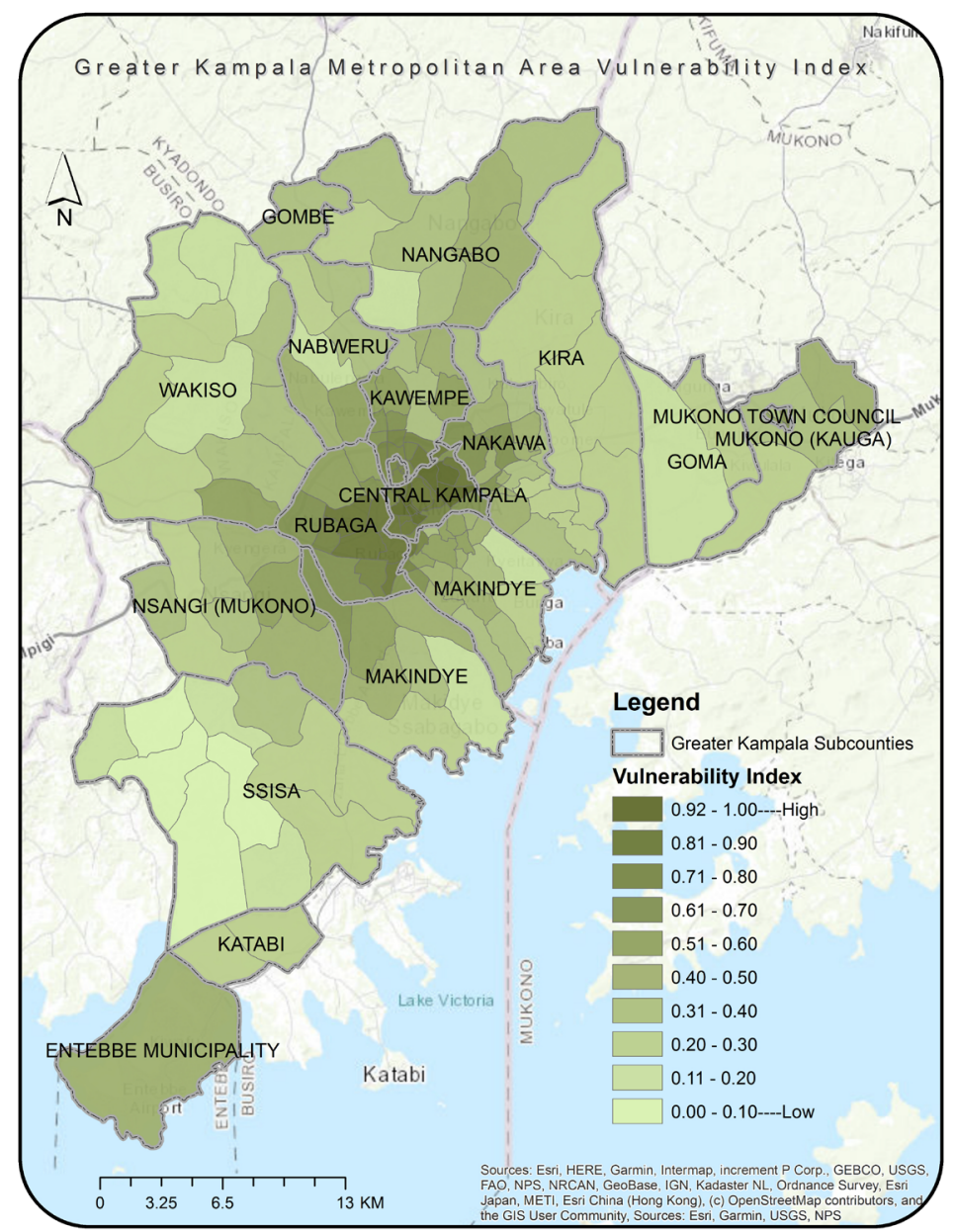

Figure 6. Vulnerability index of greater Kampala metropolitan area. 
transport hubs. These areas have a low adaptive capacity and should have resources allocated to them to increase their resilience, fortunately, the social amenities responsible for high exposure are low in these areas, however, the sporadic nature of susceptibility and individual level calls for sensitization and travel restrictions to such areas.

\subsection{Visualization}

An open web map series was developed on the ArcGIS online infrastructure to transform the mapping from static to dynamic. The dynamic maps as shown in Figure 7 enable the interactive interrogation of the vulnerability indices to detail. A vulnerability matrix was developed grouping the exposure, susceptibility, adaptive capacity, and vulnerability as shown in Figure 8, this quickens data access and comparison outside map interpretation.

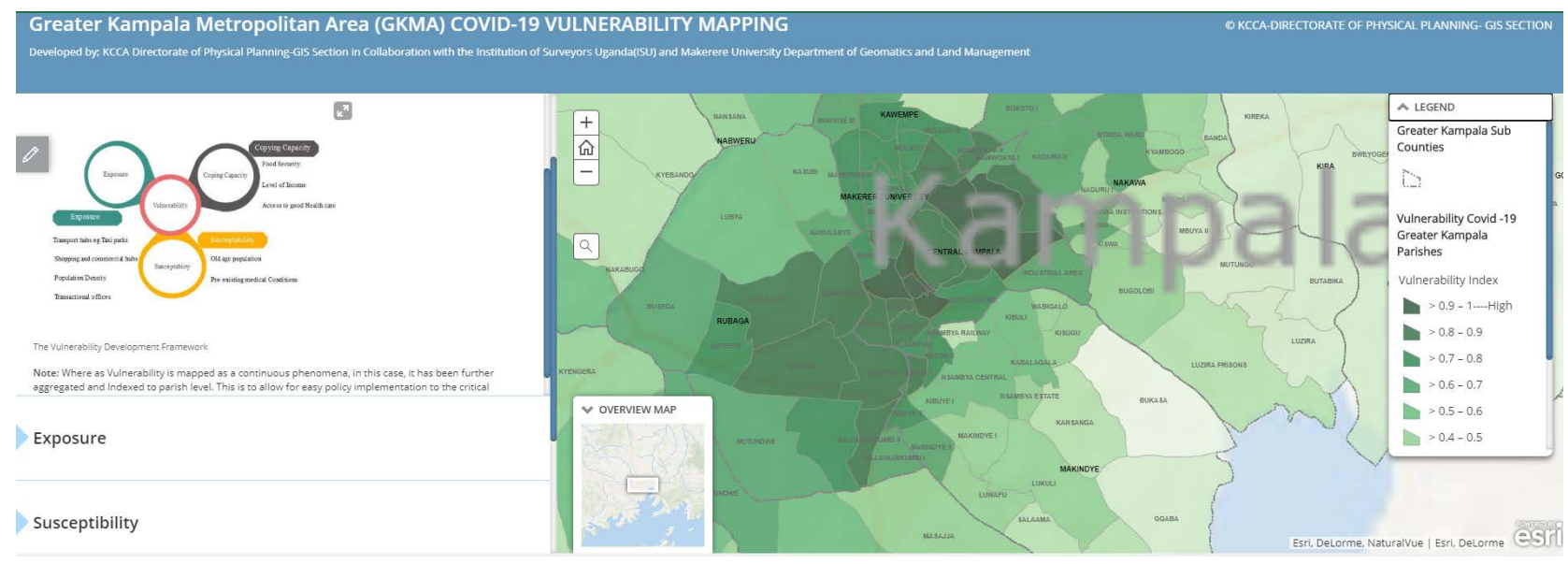

Figure 7. Hosted Vulnerability indices platform.

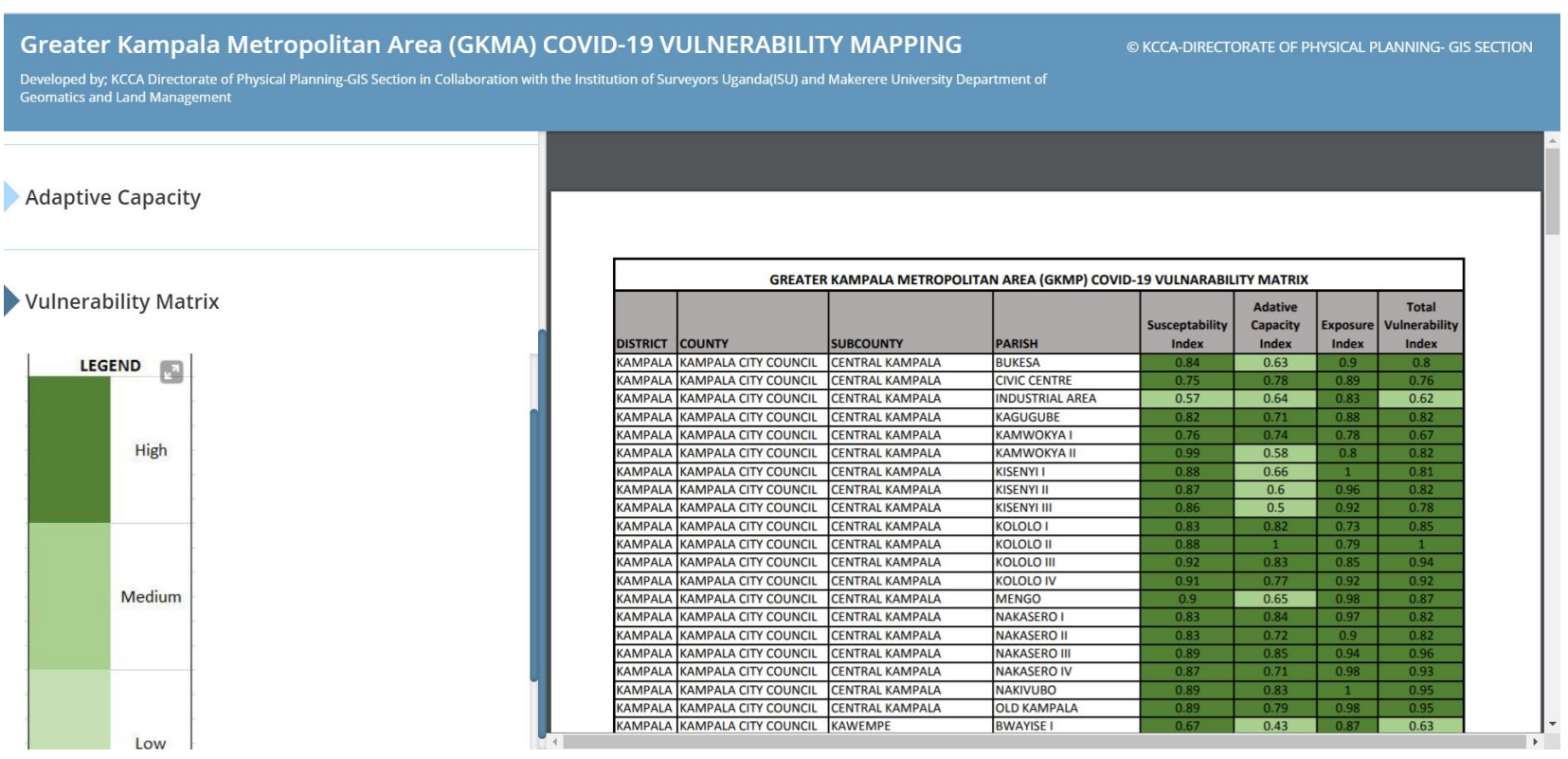

Figure 8 . The vulnerability matrix. 


\section{Conclusion and Recommendations}

The challenges COVID-19 pandemic asserts on public health are critical and innovation is central. This paper presents a spatial approach for assessing socio-economic vulnerability in the GKMA. Based on expert opinion on the prevailing novel Coronavirus COVID-19, spatially driven indicators were generated to assess vulnerability. Through an online survey and auxiliary datasets, these indicators were obtained, transformed, classified, and weighted based on the vulnerability framework. These were spatially modeled to assess the exposure, susceptibility, adaptive capacity, and vulnerability indices. The resultant continuous indices were aggregated, explicitly zoned, classified, and ranked on a continuum of high, moderate, and low based on administrative units called parishes. The results create a parish by parish variation in socio-economic vulnerability that rewards policy with the "where" information to channel regulatory resources to the highly exposed and vulnerable major towns, increase adaptability in the peri-urban areas, and infuse a socio distancing workflow in the highly susceptible areas. This essentially ensures that localities are empowered to obtain and sustain resilience through evidence-based decision making.

\section{Conflicts of Interest}

The authors declare no conflicts of interest regarding the publication of this paper.

\section{References}

[1] WHO (2020) Coronavirus Disease (COVID-19) Outbreak. https://www.who.int/emergencies/diseases/novel-coronavirus-2019

[2] El-Sadr, W.M. and Justman, J. (2020) Africa in the Path of Covid-19. New England Journal of Medicine. https://doi.org/10.1056/NEJMp2008193

[3] Nkengasong, J.N. and Mankoula, W. (2020) Looming Threat of COVID-19 Infection in Africa: Act Collectively, and Fast. The Lancet, 395, 841-842. https://doi.org/10.1016/S0140-6736(20)30464-5

[4] Uganda Response to Covid-19 (2020). https://www.health.go.ug/document/update-on-the-covid-19-response-in-uganda

[5] Uganda Bureau of Statistics (2016) The National Population and Housing Census 2014: Main Report [Internet]. 1-105.

[6] Lv, M., et al. (2020) Coronavirus Disease (COVID-19): A Scoping Review. Eurosurveillance, 25. https://doi.org/10.2807/1560-7917.ES.2020.25.15.2000125

[7] Füssel, H.-M. (2007) Vulnerability: A Generally Applicable Conceptual Framework for Climate Change Research. Global Environmental Change, 17, 155-167. https://doi.org/10.1016/j.gloenvcha.2006.05.002

[8] de Mattos, A., Cristina, M., Caiaffa, W.T., Assunçao, R.M. and Proietti, F.A. (2007) Spatial Vulnerability to Dengue in a Brazilian Urban Area during a 7-Year Surveillance. Journal of Urban Health, 84, 334-345. https://doi.org/10.1007/s11524-006-9154-2

[9] Rudiarto, I. (2019) The Spatial Pattern of Dengue Fever Risk in Semarang City. IOP Conference Series: Earth and Environmental Science, 313, Article ID: 012008. 
https://doi.org/10.1088/1755-1315/313/1/012008

[10] Bardosh, K.L., Ryan, S.J., Ebi, K., Welburn, S. and Singer, B. (2017) Addressing Vulnerability, Building Resilience: Community-Based Adaptation to Vector-Borne Diseases in the Context of Global Change. Infectious Diseases of Poverty, 6, 166. https://doi.org/10.1186/s40249-017-0375-2

[11] Stanturf, J.A., Goodrick, S.L., Warren Jr., M.L., Charnley, S. and Stegall, C.M. (2015) Social Vulnerability and Ebola Virus Disease in Rural Liberia. PLoS ONE, 10, e0137208. https://doi.org/10.1371/journal.pone.0137208

[12] Kajero, O., Del Rio Vilas, V., Wood, J.L.N. and Lo Iacono, G. (2019) New Methodologies for the Estimation of Population Vulnerability to Diseases: A Case Study of Lassa Fever and Ebola in Nigeria and Sierra Leone. Philosophical Transactions of the Royal Society B, 374, Article ID: 20180265. https://doi.org/10.1098/rstb.2018.0265

[13] Bardosh, K.L., Ryan, S., Ebi, K., Welburn, S. and Singer, B. (2017) Addressing Vulnerability, Building Resilience: Community-Based Adaptation to Vector-Borne Diseases in the Context of Global Change. Infectious Diseases of Poverty, 6, 166. https://doi.org/10.1186/s40249-017-0375-2

[14] Sutherst, R.W. (2004) Global Change and Human Vulnerability to Vector-Borne Diseases. Clinical Microbiology Reviews, 17, 136-173. https://doi.org/10.1128/CMR.17.1.136-173.2004

[15] United Nations/International Strategy for Disaster Reduction (UN/ISDR) (2004) Living with Risk: A Global Review of Disaster Reduction Initiatives. United Nations, Geneva.

[16] United Nations Development Programme (UNDP) (2004) Reducing Disaster Risk: A Challenge for Development. A Global Report, UNDP-Bureau for Crisis Prevention and Recovery (BRCP), New York.

[17] Adger, W.N., Brooks, N., Bentham, G., Agnew, M. and Eriksen, S. (2004) New Indicators of Vulnerability and Adaptive Capacity. Technical Report 7, Vol. 122, Tyndall Centre for Climate Change Research, Norwich.

[18] Birkmann, J. (2006) Measuring Vulnerability to Promote Disaster-Resilient Societies: Conceptual Frameworks and Definitions. In: Birkmann, J., Ed., Measuring Vulnerability to Natural Hazards. Towards Disaster Resilient Societies, United Nations University Press, Tokyo, 9-54.

[19] Taubenböck, H., Goseberg, N., Setiadi, N., Lämmel, G., Moder, F., Oczipka, M., Birkmann, J., et al. (2009) "Last-Mile" Preparation for a Potential Disaster-Interdisciplinary Approach towards Tsunami Early Warning and an Evacuation Information System for the Coastal City of Padang, Indonesia. Natural Hazards and Earth System Science, 9, 1509-1528. https://doi.org/10.5194/nhess-9-1509-2009

[20] Zhu, Q., Liu, T., Lin, H.L., Xiao, J.P., Luo, Y., Zeng, W.L., Zeng, S.Q., et al. (2014) The Spatial Distribution of Health Vulnerability to Heat Waves in Guangdong Province, China. Global Health Action, 7, 25051. https://doi.org/10.3402/gha.v7.25051

[21] Bizimana, J., Twarabamenye, E. and Kienberger, S. (2015) Assessing the Social Vulnerability to Malaria in Rwanda. Malaria Journal, 14, 2. https://doi.org/10.1186/1475-2875-14-2

[22] Onyango, E.A., Sahin, O., Awiti, A., et al. (2016) An Integrated Risk and Vulnerability Assessment Framework for Climate Change and Malaria Transmission in East Africa. Malaria Journal, 15, 551. https://doi.org/10.1186/s12936-016-1600-3

[23] Singh, S.R., Eghdami, M.R. and Singh, S. (2014) The Concept of Social Vulnerabili- 
ty: A Review from Disasters Perspectives. International Journal of Interdisciplinary and Multidisciplinary Studies, 1, 71-82.

[24] Johnson, R.B., Onwuegbuzie, A.J. and Turner, L.A. (2007) Toward a Definition of Mixed Methods Research. Journal of Mixed Methods Research, 1, 112-133. https://doi.org/10.1177/1558689806298224

[25] Organization for Economic Co-Operation and Development (2008) Handbook on Constructing Composite Indicators: Methodology and User Guide. http://www.oecd.org/std/42495745.pdf

[26] Krejcie, R.V. and Morgan, D.W. (1970) Determining Sample Size for Research Activities. Educational and Psychological Measurement, 30, 607-610. https://doi.org/10.1177/001316447003000308

[27] Jacobs, R., Smith, P. and Goddard, M. (2004) Measuring Performance: An Examination of Composite Performance Indicators. Centre for Health Economics, Technical Paper Series 29.

[28] Jayalakshmi, T. and Santhakumaran, A. (2009) Statistical Normalization and Back Propagation for Classification. International Journal of Computer Theory and Engineering, 3, 1793-8201.

[29] Belton, V. and Stewart, T. (2002) Multiple Criteria Decision Analysis: An Integrated Approach. Kluwer Academic Publishers, Boston.

https://doi.org/10.1007/978-1-4615-1495-4

[30] Drobne, S. and Lisec, A. (2009) Multi-Attribute Decision Analysis in GIS: Weighted Linear Combination and Ordered Weighted Averaging. Informatica, 33, 459-474.

[31] Malczewski, J. and Rinner, C. (2005) Exploring Multi Criteria Decision Strategies in GIS with Linguistic Quantifiers: A Case Study of Residential Quality Evaluation. Journal of Geographical Systems, 7, 249-268. https://doi.org/10.1007/s10109-005-0159-2

[32] Jyh-Rong, C. (2013) A Weighted Linear Combination Ranking Technique for Multi-Criteria Decision Analysis. South African Journal of Economic and Management Sciences, 16, 23-41. https://doi.org/10.4102/sajems.v16i5.639

[33] Malczewski, J. (2004) GIS-Based Land-Use Suitability Analysis: A Critical Overview. Progress in Planning, 62, 3-65. https://doi.org/10.1016/j.progress.2003.09.002

[34] Geldermann, J. and Rentz, O. (2007) Multi-Criteria Decision Support for Integrated Technique Assessment. In: Kropp, J. and Scheffran, J., Eds., Advanced Methods for Decision Making and Risk Management in Sustainability Science, Nova Science Publishers, New York, 257-273.

[35] Luh, J., Christenson, E.C., Toregozhina, A., Holcomb, D.A., Witsil, T., Hamrick, L.R., Ojomo, E. and Bartram, J. (2015) Vulnerability Assessment for Loss of Access to Drinking Water Due to Extreme Weather Events. Climatic Change, 133, 665-679. https://doi.org/10.1007/s10584-015-1493-0

[36] Monteith, W. (2019) Markets and Monarchs: Indigenous Urbanism in Postcolonial Kampala. Settler Colonial Studies, 9, 247-265. https://doi.org/10.1080/2201473X.2017.1409402

[37] Nyakaana, J.B., Sengendo, H. and Lwasa, S. (2007) Population, Urban Development and the Environment in Uganda: The Case of Kampala City and Its Environs. Faculty of Arts, Makerere University, Kampala. 